\title{
XIX. Theory of the connexion between the energy of electrical waves or of light introduced into a system and chemical energy, heat energy, mechanical energy, \&c. of the same
}

\author{
Meyer Wilderman Ph.D. B.Sc.
}

To cite this article: Meyer Wilderman Ph.D. B.Sc. (1903) XIX. Theory of the connexion between the energy of electrical waves or of light introduced into a system and chemical energy, heat energy, mechanical energy, \&c. of the same , Philosophical Magazine Series 6, 5:26, 208-226, DOI: $10.1080 / 14786440309462916$

To link to this article: http://dx.doi.org/10.1080/14786440309462916

$$
\text { 曲 Published online: } 15 \text { Apr } 2009 .
$$

Submit your article to this journal ए

\section{山ll Article views: 3}

Q View related articles ¿ 


\section{$\left[\begin{array}{ll}208 & ]\end{array}\right.$}

XIX. Theory of the Connexion between the Energy of Electrical Waves or of Light introduced into a System and Chemical Energy, Heat Energy, Mechanical Energy, \&c. of the same. By Meyer Wilderman, Ph.D., B.Sc. (Oxon.)*.

IN the Philosophical Transactions of the Royal Society, October 1902, the author published a paper "On Chemical Dynamics and Statics under the Influence of Light," in the appendix of which he indicated that the laws found experimentally and commnnicated there find their rational basis and explanation in thermodynamics. Here the author would like to consider the subject in a more general and detailed manner, not limiting himself to the results communicated there.

\section{A. General condition of Equilibrium of a System exposed to Light or to Electrical Wares.}

The following considerations, the author believes, apply to electrical waves and light simultaneously, for the reason that both are æether waves with a great number of properties in common. White light, as known, consists of light of different wave-lengths, and though the action of light of different wave-lengths upon a chemical system is different in a quantitative sense, the rays of different wave-lengths do not differ from one another from the qualitative aspect. We do not strictly speaking subdivide the different waves of the spectrum according to their lengths into "chemical" and "heat" rays. They all act "chemically" and all produce heat effects, and as far as the "chemical" effect is concerned the maximum and minimum "chemical" effect will fall into different places of the spectrum, depending not only upon the wave-lengths of the light, but also npon the nature of the chemical system itself. Sir William Abney showed that even the red and ultra-red parts of the spectrum also possess the property of producing chemical decomposition $\dagger$. In the same way, from the standpoint of the electromagnetic theory of light, electrical waves are not to be separated into a special category different from the light-waves - both being ather-waves of the same fundumental nature. We may safely expect that electric waves when introduced into a chemical system are, as well as light-waves, capable of producing phenomena connected with a variation of the chemical potential, even if phenomena of chemical dissociation or association, \&c., may not be directly observed, and that it will only be a matter of the proper choosing of the

* Communicated by the Author.

+ Phil. Trans. Roy. Soc. 1880 , ii. p. 65.3. 
region of the phenomena and of proper methods to illustrate this successfully.

In this communication the author will chiefly give his consideration to the phenomena he dealt with in the above experimental research, leaving the consideration of other regions to be dealt with hy subsequent investigations.

The condition of equilibrium of a homogeneous system (in the dark) is the following:

$d \mathrm{E}=t d \eta-p d v+\mu_{1} d m_{1} \ldots+\mu_{n} d m_{n} \geq 0$ (Gibbs' equation 12).

Let us now assume that the above homogeneous system with independent variables (i.e., in which the substances do not act one upon another chemically) is in equilibrium in the dark. Let this system be now exposed to some constant source of light, say to the light emitted by a perfectly black body when it is heated up to the temperature necessary for its beginning to emit light, or to the light from any other source, having the same intensity and the same composition, or to a constant source of the æther vibration of electric waves. Let us also assume that the system is always removed from the source of light by the same distance, which may be chosen ad libitum, so that the intensity of the light falling on the system always remains the same. Let us further assume that the layer of the homogeneous system is only taken very thin, or that the absorption of the light by the given system is so small that the intensity of the light falling upon the system in the different planes which are in a vertical position to the propagated rays of light, practically remains the same.

When the system with ind pendent variables is exposed to light, in the first instance it always absorbs more or less light. energy. Since no energy can be lost in nature the light absorbed mu-t of necessity transform in the system into some other form of energy. As the light absorbed does not transform into heat (molecular action) alone, even when no visible chemical reaction takes place, it must of necessity transform into some form of kinetic energy of the atoms in the molecules as well. From a molecular mechanical point of view this will mean that under the influence of light the amount of work present in the molecules in the form of energy of the atoms will increase.

Since every system, including those in which light produces no chemical change, continues to absorb light as long as it is exposed to it; since the absorption-coefficient of a substance is independent of the time of its exposure to the light, and since no energy can be lost in vature, we further arrive at the following conclusion : Either the system is able to store an infinite amount of energy coming from any source of light, if it is only infinitely long exposed to it, which is an impossi-

Phil. Misg. S. 6. Vol. 5. No. 26. Feb. 1903. 
bility-or, when light transforms into heat and into the new kinetic energy of the atoms, the ratio of the amount of light transformed into heat to that transformed into atomic motion is not constant. This further leads us to the conclusion that having a system with independent components, i.e., which do not act one upon another chemically, the new energy of vibrations of the atoms in the molecules, as caused by the light, will for the given conditions gradually arrive at a maximum, after which the light will exert no further additional strain upon the atoms, and the total amount of light which is further absorbed by tho system will completely transform into heat.

This maximum ralue of the new kinetin energy, stored in the system at given conditions of equilibrinm, is thus for each substance a perfectly definite one. It is for each substanee of the system directly proportional to its quantity or mass in the system, and each of the substunces gets its own peculiar new properties of motion, a new additionil potential.

The above couception being most general and fundamental, it requires experimental evidence of an immediate kind : it ought not to depend upon results obtained in a more remote minner only-such as velocity of chemical combination, \&e. The author succeeded in procuring such evidence; two plates of the same metal (fig. 1) connected with the gal ranometer and immersed in a conducting liquid, are specially prepared and treated so that the electromotive force in the dark is almost zero. One of the plates is then exposed to the light, while the other is kept in the dark. A deflexion of the galvanometer is obtained (Becquerel, Minchin, Bose, and my own experiments). These phenomena seemed to be of a very complicated nature, more Fig. 1.

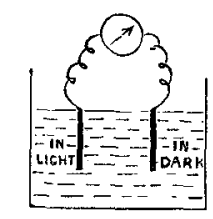
in the nature of an electrical disturbance, because as many different curves in shape and form were obtained as experiments were made; but after much tronble the author succeeded by more careful arrangement of the experiments, and especially owing to the fortunate possession of a constant source of light, in reducing the apparently numerous forms of the curves to two forms only, which in reality constitute one, and thus in arriving at the much needed general law; giving their meaning and content. These confirm the above conceptions formed first in order to explain the laws of chemical staties and dynamics in light in all their details, namely :-(1) There is not only an electrical disturbance created by the light which shows itself in all sorts of ways and then, apparently, often dis- 
appears, but the plate in the light always gradually assumes (passing through an induction period) constant new properties; a constant new electromotive force is created, which is to be seen on the photographed curve, from a line parallel to the line in the dark. Dozens of photographed curves obtained with different metals establish this generalization. (2) The electromotive force is directly proportional to the intensity of light and is a function of its composition.

Thus in the above equation (12) new terms $\lambda_{1} d m_{1}, \lambda_{2} d m_{2} \ldots$ $\lambda_{n} d m_{n}$ will be added to indicate the new kinetic energy stored by light in the different components of the system.

Further reflection leads to the conclusion that this variation in the energy of the system under the action of light cannot remain without effect upon the entropy of the system. In the general equation (12) $t d \eta$ is the thermal energy of the system, and since the same consists not only of molecular but also of atomic motion, it cumnot, therefore, remain the same when the atomic motion in the different molecules of the system changes under the infuence of light. We are also able to give evidence for this à priori couception; wo shall carry out for this a cyclic process at a constant temperature, making use of the following system: $\mathrm{Ag}_{2}$ (or $\left.\mathrm{Ag}_{2} \mathrm{Cl}\right)+\left(\mathrm{Cl}_{2}\right.$ $=2 \mathrm{AgCl}$. It is known that $\mathrm{Ag}_{2}$ (or $\mathrm{Ag}_{2} \mathrm{Cl}$ ) and $\mathrm{Cl}_{2}$ combine in the dark completely to $\mathrm{AgCl}$. It is also known that $\mathrm{AgCl}$ decomposes under the action of light either into $\mathrm{Ag}_{2}$ and $\mathrm{Cl}_{2}$ or into $\mathrm{Ag}_{2} \mathrm{Cl}$ and $\mathrm{Cl}_{2}$ (this point is undecided yet); and consequently if $\mathrm{AgCl}$ is exposed to light in a closed vessel, this decomposition of $\mathrm{AgCl}$ will go on for so long until just as much $\mathrm{AgCl}$ is formed in the unit of time from $\mathrm{Ag}_{2}$ (or $\mathrm{Ag}_{2} \mathrm{Cl}$ ) and $\mathrm{Cl}_{2}$, as $\mathrm{AgCl}$ decomposes under the action of light into $\mathrm{Ag}_{2}$ (or $\mathrm{Ag}_{2} \mathrm{Cl}$ ) and $\mathrm{Cl}_{2}$; the system will then be in a state of equilibrium, i.e.,

$$
\mathrm{Ag}_{2}\left(\mathrm{Ag}_{2} \mathrm{Cl}\right)+\mathrm{Cl}_{2} \underset{\leftarrow}{\rightarrow} \mathrm{AgCl} \text {. }
$$

Let us now assume we have at the temperature $t$ the system $\mathrm{Ag}_{2}$ (or $\mathrm{ClAg}_{2}$ ) $+\mathrm{Cl}_{2}=2 \mathrm{AgCl}$, exposed to light, in equilibrium. The same is in a cylinder with a piston, which moves without friction, and exerts a pressure upon the gas $\mathrm{Cl}_{2}$ contained in the same of one atmosphere, the $\mathrm{Ag}_{2}$ or $\mathrm{AgCl}$ or $\mathrm{Ag}_{2} \mathrm{Cl}$ and A gCl being solid. Let the quantity of $\mathrm{Cl}_{2}$ be $=1 \mathrm{gr}$. molec.; it Fig. 2. will occuly the space of 22 litre- 
Now we carry out the following isothermal process :-

1. We remove the light from the same : the $\mathrm{Cl}_{2}$ will combine with the $\mathrm{Ag}_{2}$ (or $\mathrm{Ag}_{2} \mathrm{Cl}$ ) giving 2 gr. mol. $\mathrm{AgCl}$. During this process of combination the work done by the piston against the system will be $g v=\mathrm{RT}$; $A p v=$ very nearly 2 cal., which will be given to the system; the heat of the reaction of the combination in the dark will be $\mathrm{W}_{d}$, and this will be taken from the system.

2. Now we expose the system to light. It will take up energy from the light, and the light-kinetic energy used up, during the reaction will be $\mathrm{E}_{l}$; if $\mathrm{I}$, be the light-kinetic equivalent of heat, $L_{L} E_{l}$ is given to the system during the reaction in light. During this reaction $1 \mathrm{gr}$. mol. $\mathrm{Cl}_{2}$ is formed, which keeps $\mathrm{Cl}_{2}, \mathrm{AgCl}, \mathrm{Ag}_{2}$ (or $\mathrm{A}_{2} \mathrm{Cl}$ ) in equilibrium; the work done $b y$ the system is $-p v=-\mathrm{R}^{\mathrm{T}}$; $-\mathrm{A} p v=-2 \mathrm{cal}$., and the heat of reaction of dissociation in light is $W_{l}$ and this is given to the system. The system is thus again in the same state from which we started, therefore $-\mathrm{W}_{d}+\mathrm{W}_{l}+\mathrm{LE}_{l}=0$, i. e., the heat of the same raction is at the same temperature in light not the same as in the dark. If $\mathrm{W}_{d}$ is negative, $\mathrm{W}_{l}$ is $<W_{d}$; if $W_{d}$ is positive, $W_{l}$ is $>W_{d}$. Now in the equation $d \mathrm{E}=t d \eta-p d v, t d \eta$ is the hent taken up by the system (positive or negative) when it is passing from one state to another. Therefore at the same temperature $t$ in the light $t d \eta^{\prime}$ or $\mathrm{W}_{l}$ is different from $t d \eta$ or $\mathrm{W}_{d}$ in the dark.

Further, the exposure of the system to light cannot very often remain without a change in the mechanical energy $p d v$ of the system, namely, when chemical transformations take place in the same. It is, however, not impossible that this is also the case even when no chemical transformation takes place in the system, however small this change in the value of $p d v$ may be, considering that the pressure of a gas at at constant volume ought to change with the variation of the kinetic energy of the atoms and nolecules. Thus our previous equation for equilibrium of a system with independent variables assumes when it is exposed to the light or to the action of electric waves, and when the heat produced by the absorbed light is removed from the system (say by the surrounding bath of a constant temperature $t$ ), the following form :-

$$
\begin{aligned}
& d \mathrm{E}+d \mathrm{E}_{1}=d \mathrm{E}^{\prime}
\end{aligned}
$$

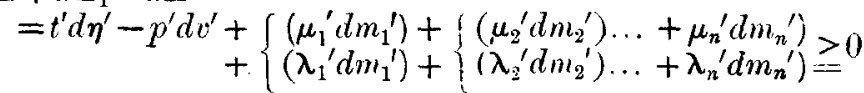

where $\mathrm{E}^{\prime}$ is the total energy of the system in light, $\eta^{\prime}$ its entropy, $v^{\prime}$ the volume, $t^{\prime} \eta^{\prime}$ the thermal energy, $\mu^{\prime} v^{\prime}$ the mechanical energy in light, $\left(\mu_{1}{ }^{\prime} m_{1}{ }^{\prime}\right),\left(\mu_{2}{ }^{\prime} m_{2}{ }^{\prime}\right) \ldots\left(\mu_{n_{n}}{ }^{\prime} m_{n}{ }^{\prime}\right)$ is its chemical energy, and $\left(\lambda_{1}^{\prime} m_{1}^{\prime}\right),\left(\lambda_{2}^{\prime} m_{2}^{\prime}\right) \ldots\left(\lambda_{p}^{\prime} m_{n}^{\prime}\right)$ the new 
kinetic energy stored in the components of the system under the action of light. The connexion between the terms $\left(\lambda_{1}^{\prime} d m_{1}^{\prime}\right) \ldots\left(\lambda_{n}{ }^{\prime} d m_{n}{ }^{\prime}\right)$ and $\left(\mu_{1}{ }^{\prime} d m_{1}^{\prime}\right) \ldots\left(\mu_{n}{ }^{\prime} d m_{n}{ }^{\prime}\right)$ now requires special consideration.

What is to be understood by "the energy stored in the atoms of the molecules, when the same are exposed to light" ? It is a thermodynamic necessity that the light absorbed by the system (which in this case we assume to represent a thin layer) should transform into some other form of kinelic energy of the atoms, and that at the same time this new energy should be directly proportional to the total mass of each component, i.e., that the new energy created in the sys'em should be of the form $\left(\lambda_{1}{ }^{\prime} d m_{1}{ }^{\prime}\right) \ldots\left(\lambda_{n}{ }^{\prime} d m_{n}{ }^{\prime}\right)$. This, however, does not disclose the nature of this kinetic energy itself. A glance at the above equation (A) shows that more than one interpretation of the terms $\left(\lambda_{1}^{\prime} d m_{1}{ }^{\prime}\right) \ldots\left(\lambda_{n}^{\prime} d m_{n}{ }^{\prime}\right)$ is possible, and these interpretations entirely depend upon how the ultimate nature of the energy stored in the atoms of the molecules under the action of light is conceived.

One conception is that the light-kinetic potentials $\left(\lambda_{1}{ }^{\prime}\right)$, $\left(\lambda_{2}{ }^{\prime}\right) \ldots\left(\lambda_{n}{ }^{\prime}\right)$ are identical in nature with the chemical potentials $\left(\mu_{1}^{\prime}\right),\left(\mu_{2}^{\prime}\right) \ldots\left(\mu_{n}^{\prime}\right)$. In this case it will mean that the kinetic energy stored in the atoms under the influence of light $\left(\lambda^{\prime} d m_{1}^{\prime}\right) \ldots\left(\lambda_{n}{ }^{\prime} d m_{n}{ }^{\prime}\right)$ is nothing else than chemical energy; it will mean that under the influence of light the chemical potentials of all and the same substances always increase (simply from one value to another). In the light of this conception, when light-energy is absorked by any system so far as it does not transforil into heat it always transforms into chomical energy.

This conception would have the advantage of enabling us, in the consideration of the systems in which the variables are dependent one upon another, at once to see that the laws which must govern the two impartant regions of chemical statics and dynamics under the action of light, must be those found experimentally by the author and communicated in the Philosophical Transactions. It carries, however, little conviction for systems with independent variables where no chèmical transformation is to be perceived. There are important regions of phenomena-such as phenomena of absorption, dispersion, refraction, fluorescence, \&c., for which the assumption that the energy stored in the molecules and atoms under the action of light cannot transform into chemical energy alone, but must also generate an energy sui generis, becomes almost imperative. In the mechanical kinetic explanation of the above phenomena, Stokes, Helmholtz, Lommel, and others, have to assume that 
when light is passing through a system it creates new periodically oscillating movements of the atoms or molecules which are similar to those of the æother waves of the light themselves (this kind of new energy can well be called "light-kinetic energy of the atoms or molecules"). Since the theoretical investigations of the above regions of phenomena on the hasis of the above mechanical conceptions met no doubt with great success, having found in the quintessence extensive confirmation in the numerous experimental investigations undertaken for their test, it is only expedient that in the consideration of the subject from a thermodynamic or energetic point of view the formed conceptions should be brought into concord, if possible, with the conceptions of Stokes, Helmholtz, and others. The author has been trying to find a more direct experimental decision upon this very fundamental point, and he believes he has succeeded in the following manner:-If the action of light consisted in the increase in the chemical potential only, then the current generated under the action of light should according to Gitld' equations, p. 503, $v^{\prime \prime}-v^{\prime}=\alpha_{a}\left(\mu_{a}^{\prime}-\mu_{a}^{\prime \prime}\right)$ and $v^{\prime \prime}-v^{\prime}=\alpha_{g}\left(\mu_{g}^{\prime \prime}-\mu_{g}^{\prime}\right)$ always go in ONE direction. The author finds that the same metallic plates give in different mediums, at one time a current from the plate in the light to that in the dark, at anotber time in the opposite direction, and also that different metaliic plates give in the same medium currents in opposite directions.

Thus the author conceives that the new kinetic energy of the atoms, stored in them under the influence of light, does not transform into chemical energy alone, but into chemical energy and into a light-kinetic energy sui generis at the same time. In other words, the terms $\left(\lambda_{1}{ }^{\prime} d m_{1}{ }^{\prime}\right) \ldots\left(\lambda_{n}{ }^{\prime} d m_{n}{ }^{\prime}\right)$ must be decomposed into two parts $v_{1} d m_{1}^{\prime}, v_{2} d m_{2}{ }^{\prime} \ldots \nu_{n} d m_{n}{ }^{\prime}$ (chemical energy), and $\lambda_{1}{ }^{\prime} d m_{1}{ }^{\prime}, \lambda_{n}{ }^{\prime} d m_{n}{ }^{\prime}$ (kinetic energy *ui gentris for which we may conveniently retain the term "lightkinetic energy," $\lambda_{1}{ }^{\prime}, \lambda_{2}{ }^{\prime} \ldots \lambda_{n}{ }^{\prime}$ being the light-kinetic potentials), which like gravitation is bound on the same components, but is not identical with chemical energy.

The equation for the system in the dark being

$$
d \mathrm{E}=t d \eta-p d v+\mu_{1} d m_{2} \ldots+\mu_{n} d m_{n} \geq 0, \quad . \quad .
$$

it thus transforms in light into another

$$
d \mathrm{E}^{\prime}=t^{\prime} d \eta^{\prime}-p^{\prime} d v^{\prime}+\mu_{1}{ }^{\prime} d m_{1}{ }^{\prime}+\lambda_{1}{ }^{\prime} d m_{1}{ }^{\prime} \ldots+\mu_{n}{ }^{\prime} d m_{n}{ }^{\prime}+\lambda_{n}{ }^{\prime} d m_{n}{ }^{\prime} \geq 0
$$
where $\left(\mu_{1}{ }^{\prime}\right)+\nu_{1}=\mu_{1}{ }^{\prime} \ldots\left(\mu_{n}{ }^{\prime}\right)+\nu_{n}=\mu_{n}{ }^{\prime}$, \&c., the values of $\mu^{\prime}, \lambda^{\prime}$ being a function of the intensity of light and its composition, of the nature of the components of the surrounding medium, \&c. 
B. The Effect of Light upon the Induction and Deduction Periods and upon other Properties of Matter* ${ }^{*}$.

Since now it is the light prssing through the system which is producing the new light-kinetic energy of the atoms and the new additional chemical energy of the molecules of the system, and this is a time process, it follows that it is a thermodynamic necessity that all the systems without exception (since all systems absorb light), those with independent as well as those with dependent variables of composition, should arrive at their new state of maximum kinetic energy, passing first through a period of gradual approximation to the same. This period is called the "induction" period.

Experimental evidence:-

1. Such an induction period we find when light is acting upon one of the two plates of the same metal, while the other plate is kept in the dark, in the arrangement before mentioned. Here we have a system with independent variables of composition, where no chemical reaction takes place in the same under the action of light, though a gradual increase in the chemical and a creation and increase of the light-kinetic energy, no doubt, take place, because if the chemical potential remained the same at the two surfaces of the plates, no electromotive force could be generated. We may call it the induction period of energy.

2. Such a period of induction we find for the system with dependent variables of composition, i.e., where a chemical reaction takes place. It was found by the author* that the velocity-constant of chemical combination of $\mathrm{CU}$ and $\mathrm{Cl}_{2}$ gradually increases till it reaches its constant value. Bunsen and Roscoe first observed the phenomenon of "chemical induction" in their investigation of the combination of chlorine and hydrogen under constant conditions. The phenomenon, however, is of a more complicated nature than conceived by Bunsen and Roscoe. Here we have to deal with two periods: one of induction of energy, the other of chemical induction already found by Bunsen and Roscoe. Indeed chemical combination does not usually start at once on exposure to light, but the system first passes through a latent period during which no chemical reaction can be perceived by the most delicate means, but a gradual increase of the stored energy in form of chemical energy and in form of a kinetic energy sui generis undoultedly takes place in the same manner as in the case of the metallic plates mentioned above. When

* See the author's paper "On Chemical Statics and Dynamics under the Influence of Light," Philosophical Transactions of the Royal Society, October 1902, pp. 378-391. 
the stored energy is great enough to shatter the bonds between the atoms in the molecules, a new chemical rearrangement between the atoms takes place-the chemical induction period starts. As the light-energy is further absorbed by the system, the chemical and light-kinetic potentials further increase, the velocity-constant of the reaction increases (period of chemical induction), until as mentioned before no more strain is exerted by light on the atoms in the molecules, and the impulses of the æther-waves prevent the atoms and molecules from losing their state of maximum energy, keeping them up in the same state of maximum kinetic energy. It is well possible to conceive that the ratio of the amount of light-energy transformed into chemical energy to the amount transformed into light-kinetic energy sui generis is not always the same, and this may account for the fact that it takes a time before chemical induction starts. But during both periods - the induction period of energy and the chemical induction period-both the chemical and the lighit-kinetic potentials must change at the same time, as is to be seen from the fact that with metallic plates an electromotive force is instantanennsly obtained on exposure of one plate to light.

Besides the period of induction, a period of chemical "deduction" must equally be considered. This, as well as the induction period, is a thermodynamic necessity. When light is removed from the system, and the maximum kinetic energy of the atoms is no longer kept up by the impulses of the æther-waves, the new kinetic energy of the atoms which has been acquired in light will use itself up, i.e., the atoms and the molecules will sooner or later return to their old state which they had in the dark. In what manner will the kinetic energy of the atoms-previously created by lightuse itself up in the dark? If the system consists of independent components it will evidently transform into heat. This we find with metallic plates mentioned before; and this period, during which the chemical potential of the plate previously exposed to light gradually assumes its former value, while its light-kinetic potential gradually disappears, may appropriately be called "the deduction period" of energy. If again under the influence of light a reaction was going on in the system which was not going on previously in the dark, then the above-acquired kinetic energy will partly be used up during the reaction as long as it will still continue to go on in the dark, and partly transform into heat. This period of deduction is naturally also a time process, as the process of induction is; it represents to some extent the 
reverse phenomenon to the last, $i$. e., during this period the kineic energy acyuired under the influence of light gradually fills from its maximum to zero. Experimental evidence for the deduction period is given in the experimental investigation of the velocity of combination of $\mathrm{CO}$ and $\mathrm{Cl}_{2} *$. As in the case of the induction period, here we miust also distinguish between the two periods-the "chemical" deduction period at the beginning when light is removed, usually lasting only a short time (the reaction stops), and the much longer "deduction period of energy." Though chemical reaction very soon stops in the system, it is still in another state of energy, and it only gradually returns to its previous state of energy in the dark before the illumination. This was shown by the author on the length of the induction periods on fresh exposures of the system $\mathrm{CO}+\mathrm{Cl}_{2}$ to light. $A s$ in the case of the induction period, both the acquired new chemical and the light-kinetic energy decrease simultaneously during the two periods of deduction. It may be, however, that the ratio of the newly-acquired chemical energy to that of the newly-acquired light-kinetic energy still remaining in the system on removal of light, is not alwars the same during the period of deduction. The induction and the deduction period evidently equally concern systems in which chemical reaction goes on both in the light and in the dark, but with different speeds $\left(\mathrm{H}_{2} \mathrm{O}_{2}\right)$, or systems in which a reaction goes on in light only $\left(\mathrm{CO}+\mathrm{Cl}_{2}\right.$ or $\mathrm{H}_{2}+\mathrm{Cl}_{2}$ ). It further follows that if atter the deduction period is completed the system should again be exposed to the light, the system will evidently have to pass again through a period of induction; and if the light should be again removed from the system, a new deduction period will have to follow. Also, that during the induction period, i. e., before the constant maximum of kinetic energy is reached, the longer the system was previously exposed to the induction, the longer will be the deduction period through which the system passes to the old state, and that, after the induction period has passed and the maximum reached, the deduction period will always last the same time, however long the system may have been exposed to the light; so also the less the system reached the old state, $i$.e., the less the deduction period is completed, the shorter is the induction period when it is again exposed to the light; it is also evident that both the induction and deduction periods must naturally depend upon the chemical composition of the system at the different times, and upon the intensity and

* Pliil. Trans. 199 A, p. 337. 
wave length of the rether-vibrations. All these detailed conclusions, which here follow as a necessity from purely thermodynamic considerations, find their experimental verification in the above-mentioned research, published in tho Philosophical Transactions of the Royal Society, Oct. 1902, and will be further given in the author's research with metallic plates, which will be communicated in due course.

Since the introduction of light into the system with independent variables of composition changes in any case their chemical potentials, and with it their chemical energy, it is evident that all those plysical and chemical phenomena which in one way or another are dependent upon the chemical potentials of the components of a system, such as the electromotive force, the surfare-tension, dec, will also undergo a variation when the system is exposed to light. As all these phenomena are either changed or created by the variation of the chemical potentials of the components, they will change under the influence of light in the same manner as the chemical potentials do, i. e., they will all have under the action of light their induction and deduction periods, with all the properties of the same which were mentioned above, and after the induction period has passed they will all reach a constant value corresponding to the maximum variation of the kinetic energy absorbed by the system under the action of light.

\section{Chemical Statics and Dynamics under the Influence of Light*}

It remains to be seen what are the results obtainel for equilibrium and for velocity of reaction when each of the components of the system has not only a (new) chemical potential, but also a light-linetic potential.

If we integrate the equation

$d \mathrm{E}+d \mathrm{E}_{1}=d \mathrm{E}^{\prime}=t^{\prime} d \eta^{\prime}-\mu^{\prime} d v^{\prime}+\mu_{1}^{\prime} d m_{1}^{\prime}+\lambda_{1}^{\prime} d m_{1}^{\prime} \ldots \mu_{n}^{\prime} d m_{n}{ }^{\prime}+\lambda_{n}{ }^{\prime} d m_{n}$, under the supposition that the quantity of the mass of the given layer or system (under conditions mentioned on p. 209) with independent variables of composition increases from zero to a finite value, while the nature and state of the system remain the same, we get

$$
\mathrm{E}+\mathrm{E}_{1}=\mathrm{E}^{\prime}=t^{\prime} \eta^{\prime}-p^{\prime} v^{\prime}+\left(\mu_{1}^{\prime}+\lambda_{1}{ }^{\prime}\right) m^{\prime} \ldots+\left(\mu_{n}{ }^{\prime}+\lambda_{n}{ }^{\prime}\right) m n^{\prime} \text {. }
$$

Differentiating the same in the most general way:

$$
\begin{aligned}
d \mathrm{E}^{\prime}= & t^{\prime} d \eta^{\prime}+\eta^{\prime} d t^{\prime}-p^{\prime} d v^{\prime}-v^{\prime} d p^{\prime}+\left(\mu_{1}^{\prime}+\lambda_{1}^{\prime}\right) d m_{1}^{\prime} \\
& +\frac{1}{2} m_{1}^{\prime} d\left(\mu_{1}^{\prime}+\lambda_{1}^{\prime}\right) \ldots+\left(\mu_{n}^{\prime}+\lambda_{n}^{\prime}\right) d m_{n}{ }^{\prime}+m_{n}^{\prime} d\left(\mu_{n}{ }^{\prime}+\lambda_{n}{ }^{\prime}\right),
\end{aligned}
$$

* See author's paper under the same heading in the Phil. Trans. of the Royal Society, October 190:2, pp, 376-895. 
and subtracting from this equation (i.) we get

$\eta^{\prime} d t^{\prime}-v^{\prime} d p^{\prime}+m_{1}{ }^{\prime} d \mu_{1}{ }^{\prime}+m_{1}{ }^{\prime} d \lambda_{1}{ }^{\prime} \ldots+m_{n}{ }^{\prime} d \mu_{n}{ }^{\prime}+m_{n}{ }^{\prime} d \lambda_{n}{ }^{\prime}=0$.

Here we have a connexion between $2 n+2$ variables $t^{\prime}, p^{\prime}, \mu^{\prime} \ldots \mu_{n}{ }^{\prime}, \lambda_{1}{ }^{\prime} \ldots \lambda_{n}{ }^{\prime}$. If this connexion is known, the equation concerning $\eta^{\prime}, v^{\prime}, m_{1}{ }^{\prime} \ldots m_{n}{ }^{\prime}$, which are functions of the same variables, will be known as well, and we shall have in the total $n+2$ such independent equations. Here, however, $d \mu$ is not independent of $d \lambda$. General considerations of the conditions of equilibrium of a chemical system in light lead to the conclusion that for this the temperature, the pressure, and the sum of the chemical and of the light-kinetic potentials of each of the components must be constant through the whole system. Therefore

$$
\mu_{1}{ }^{\prime}+\lambda_{1}{ }^{\prime}=\mathrm{C}_{1}{ }^{\prime}, \quad \mu_{n}{ }^{\prime}+\lambda_{n}{ }^{\prime}=\mathrm{C}_{n}{ }^{\prime} . \quad \text {. . . }
$$

Thus we have in the total $2 n+2$ equations for the $2 n+2$ variables $t^{\prime}, p^{\prime}, \mu_{1}{ }^{\prime}, \lambda_{1}{ }^{\prime} \ldots \mu_{n}{ }^{\prime}, \lambda_{n}{ }^{\prime}$, and these with (ii.) give in total $2 n+3$ known equations, while the total number of variables $\mathbf{E}^{\prime}, \eta^{\prime}, t^{\prime}, \mu^{\prime}, v^{\prime}, \mu_{1}{ }^{\prime}, \lambda_{1}{ }^{\prime}, m_{1}{ }^{\prime} \ldots \mu_{n}{ }^{\prime}, \lambda_{n}{ }^{\prime}, m_{n}$ is $3 n+5$. If the system consists of one substance only, then equation (iii.) becomes

$$
\eta^{\prime} d t^{\prime}-\imath^{\prime} d p^{\prime}+m_{1}^{\prime} d \mu_{1}^{\prime}+m_{1}^{\prime} d \lambda_{1}^{\prime}=0 .
$$

Equations (iii.) and $(\gamma)$ give the variation of temperature, or of pressure, or of chemical, or of the ilght-kinetic potential, or of several of them with the variation of one or some of the variables when all the rest of the variables remain constint.

In case of a gas-mixture there is every reason to assume that the energy, pressure, density (i. e., $\mathrm{E}^{\prime}, p^{\prime}$, and $\frac{m^{\prime}}{v^{\prime}}$ ), temperature, entropy, potentials of each of the gases separately are the same when they are together as they would be if they were alone, provided that the gases do not act one upon another chemically. This is an extension of Dalton's liw applied not only to pressures but to all other thermodynamic factors of the same. Thus the variation of temperature or of the chemical potentials and of the light-kinetic potentials of each of the gases in dependence upon the variation of all the rest will be the same as if the system consisted of the given gas alone.

Making use of functions $\psi^{\prime}, \chi^{\prime}, \zeta^{\prime}$, introduced by Gibbs in his treatment of heterogeneous systems when no lightenergy is stored in the same, we ultimately get, putting $\mathbf{E}+\mathrm{E}_{1}-t^{\prime} d \eta^{\prime}=\psi^{\prime}$,

$$
-t^{\prime} d \eta^{\prime}-v^{\prime} d p^{\prime}+m_{1}{ }^{\prime} d \mu_{1}{ }^{\prime}+m_{2}{ }^{\prime} d \lambda_{1}{ }^{\prime} \ldots+m_{n}{ }^{\prime} d \mu_{n}{ }^{\prime}+m_{n}{ }^{\prime} d \lambda_{2}{ }^{\prime}=0 \text {. }
$$


Putting $\mathrm{E}+\mathrm{E}_{1}+p^{\prime} \boldsymbol{v}^{\prime}=\chi^{\prime}$, we get

$\eta^{\prime} d t^{\prime}+p^{\prime} d v^{\prime}+m_{1}{ }^{\prime} d \mu_{1}{ }^{\prime}+m_{1}{ }^{\prime} d \lambda_{1}{ }^{\prime} \ldots+m_{n}{ }^{\prime} d \mu_{n}{ }^{\prime}+m_{n}{ }^{\prime} d \lambda_{n}{ }^{\prime}=0$. (v.)

Putting $\mathrm{E}+\mathrm{E}_{1}-t^{\prime} \eta^{\prime}-p^{\prime} v^{\prime}=\xi^{\prime \prime}$, we get

$-t^{\prime} d \eta^{\prime}+p^{\prime} d v^{\prime}+m_{1}{ }^{\prime} d \mu_{1}{ }^{\prime}+m_{1}{ }^{\prime} d \lambda_{1}{ }^{\prime} \ldots+m_{n}{ }^{\prime} d \mu_{n}{ }^{\prime}+m_{n}{ }^{\prime} d \lambda_{n}{ }^{\prime}=0$ (vi.)

Equations iii., iv., v., vi. are Gibbs' modified fundamental equations of condition, when each of the conponents contains two potentials.

From equation (i.) we further get

$$
\mu_{1}{ }^{\prime}+\lambda_{1}{ }^{\prime}=\left(\frac{d \mathrm{E}+d \mathrm{E}_{1}}{d m_{1}^{\prime}}\right) \eta^{\prime}, v^{\prime}, m_{3}^{\prime} \ldots m_{n}^{\prime}, \ldots
$$

i.e., if we assume that to a given homogeneons mass an infinitely small quintity of $m_{1}{ }^{\prime}$ is added, while the mass remains homogeneous, and its entropy in ligbt, volume, and the rest of the substances remain constant; then the sum of the chemical and of the light-kinetic potentials of the introduced substance is equal to the ratio of the increase in the energy $\mathbf{E}$ and in the energy $\mathbf{E}_{1}$ (stored by light in the system), caused by this introduction of the substance $m_{1}{ }^{\prime}$, to the introduced quantity of $d m_{1}{ }^{*}$

It is further evident that if an equation of chemical reaction exists between the units of the substance of the system

$$
n_{1} \mathrm{~A}_{1}+n_{2} \mathrm{~A}_{2} \ldots=m_{1} \mathrm{~A}_{1}+m_{2} \mathrm{~B}_{2} \ldots, \quad . \quad \text {. }
$$

where $A_{1}, A_{2}, \ldots B_{1}, B_{2} \ldots$ are the units of the different substances, and $n_{1}, n_{2} \ldots m_{1}, m_{2} \ldots$ numbers, then if the reasoning given by Gibbs in the case of one potential be further applied to our case with two potentials, we have also

$$
n_{1}\left(\mu_{A_{1}}{ }^{\prime}+\lambda_{A_{1}}{ }^{\prime}\right)+n_{2}\left(\mu_{A_{2}}{ }^{\prime}+\lambda_{A_{2}}{ }^{\prime}\right) \ldots=m_{1}\left(\mu_{B_{1}}{ }^{\prime}+\lambda_{B_{1}}{ }^{\prime}\right)+m_{2}\left(\mu_{B_{2}}{ }^{\prime}+\lambda_{B_{2}}{ }^{\prime}\right) \ldots
$$

Let us now return to the consideration of the equation (iii), first when the system consists of one gaseous substance only. It assumes in the first instance the form

$$
\eta^{\prime} d t^{\prime}-v^{\prime} d p^{\prime}+m_{1}{ }^{\prime} d \mu_{1}{ }^{\prime}+m_{1}{ }^{\prime} d \lambda_{1}{ }^{\prime}=0 .
$$

Here $\eta^{\prime} d t^{\prime}, v^{\prime} d p^{\prime}, m_{1}^{\prime} d \mu_{1}^{\prime}, m_{1}{ }^{\prime} d \lambda_{1}^{\prime}$, are the variations in the

* In the same manner we have

$$
\begin{aligned}
& \mu_{1}^{\prime}+\lambda_{1}^{\prime}=\left(\frac{d \psi^{\prime}}{d m_{1}^{\prime}}\right) t^{\prime}, v^{\prime}, m_{2}^{\prime} \ldots m_{n^{\prime}}, \\
& \mu_{1}^{\prime}+\lambda_{1}^{\prime}=\left(\frac{d \chi^{\prime}}{d m_{1}^{\prime}}\right) \eta^{\prime}, p^{\prime}, m_{2}^{\prime} \ldots m_{n}^{\prime}, \\
& \mu_{1}^{\prime}+\lambda_{1}^{\prime}=\left(\frac{d \zeta^{\prime}}{d m_{1}^{\prime}}\right) t^{\prime}, p^{\prime}, m_{2}^{\prime} \ldots m_{n}^{\prime} .
\end{aligned}
$$


thermal, mechanical, chemical, and light-kinetic energy of the total mass of the system. We can naturally express the mass in any unit we may desire to adopt. I Let this unit be the gram-molecule of the gas, hecause this will allow a simple use of the gaseous laws and will also be in conformity with the form and content of the equations for chemical reaction which for many reasons were finally adopted by the chemist. I tet the total mass of the gas be $m_{1}^{\prime}$ gram-molecules. Then we have : the total chemical energy is $\mu_{1}{ }^{\prime} m_{1}{ }^{\prime}$, and the above variation in the same $m_{1}^{\prime} d \mu_{1}^{\prime}$; the total light-kinetic energy is $m_{1}{ }^{\prime} \lambda_{1}{ }^{\prime}$, and the variation in the same $m_{1}{ }^{\prime} d \lambda_{1}{ }^{\prime}$; the total mechanical energy of the mass is $p^{\prime} v^{\prime}=m_{1}^{\prime} \mathbf{R} t^{\prime}$, or nearly $=m n_{1}^{\prime}$. 2 cal., since $\left(\nu_{1}^{\prime}{ }^{\prime}{ }_{1}^{\prime}{ }^{\prime}\right)$ of 1 gr.-mol. $=\mathrm{R} t^{\prime}$, and the above variation in the same is $v^{\prime} d p^{\prime}=v^{\prime} d\left(\frac{m_{:}^{\prime} \mathrm{R} t}{v^{\prime}}\right)$, where $v^{\prime}$ is the volume of the gins; the total $\eta^{\prime}$ of the mass $=m_{1}^{\prime}\left(\frac{\mathrm{H}^{\prime}}{t^{\prime}}+\mathrm{K}_{1}^{\prime}\right)$, when $\left(d \eta^{\prime}\right)$ of $1 \mathrm{gr} .-\mathrm{mol}=\frac{d \mathrm{H}^{\prime}(\text { of } 1 \mathrm{gr}-\mathrm{mol})}{t^{\prime}}$, and $\left(\eta^{\prime}\right)$ of $1 \mathrm{gr} .-\mathrm{mol} .=\frac{\mathrm{H}^{\prime}}{t^{\prime}}+\mathrm{K}_{1}^{\prime}$, where $\mathrm{K}_{1}^{\prime}$ is an integration-constant.

Thus we get instead of (iii.)

$m_{1}{ }^{\prime}\left(d \mu_{1}{ }^{\prime}+d \lambda_{1}{ }^{\prime}\right)=m_{1}{ }^{\prime} \mathrm{R} d t^{\prime}+\mathrm{R} t^{\prime} d m_{1}{ }^{\prime}-m_{1}{ }^{\prime} \mathrm{R} t^{\prime} d \lg v^{\prime}-m^{\prime} \mathrm{H}^{\prime} d \lg t^{\prime}+\mathrm{K}^{\prime} d t^{\prime}$

and $\mu_{1}{ }^{\prime}+\lambda_{1}{ }^{\prime}=\mathrm{R} t^{\prime}+\mathrm{R} t^{\prime} \lg \frac{m^{\prime}}{v^{\prime}}-\mathrm{H}^{\prime} \lg t^{\prime}+\mathrm{K}_{1}{ }^{\prime} t^{\prime}+\mathrm{K}_{1}^{\prime \prime}$,

where $\mathrm{K}_{1}{ }^{\prime \prime}$ is another integration-constant.

Now we are entitled to assume that in the case of a gaseous mixture Dalton's law will hold good in the wider sense, nainely, not only for $\mathrm{E}=\Sigma(\mathrm{E}), p=\Sigma(\mu), \eta=\Sigma(\eta), \psi=\Sigma(\downarrow)$, $\chi=\Sigma(\chi)$, as indicated by Gibbs, but also for the chemical and the light-kinetic potentials of each gas in the gasmixture.

Having now a chemical equation of reaction expressed in gram-molecules,

$$
n_{1} \text { gr.-m. of } \sigma_{1}+n_{2} \text { gr.-m. of } \sigma_{2}=n_{3} \text { gr.-m. of } \sigma_{3},
$$

and

$$
n_{1}\left(\mu_{1}{ }^{\prime}+\lambda_{1}{ }^{\prime}\right)+n_{2}\left(\mu_{2}{ }^{\prime}+\lambda_{2}{ }^{\prime}\right)=n_{3}\left(\mu_{3}{ }^{\prime}+\lambda_{3}{ }^{\prime}\right) \text {, }
$$

we thus get

$$
\begin{aligned}
& n_{1}\left[\mathrm{R} t^{\prime} \lg \frac{{ }^{\prime \prime}{ }^{\prime}}{v^{\prime}}+\left(\mathrm{R}+\mathrm{K}_{1}^{\prime}\right) t^{\prime}-\mathrm{H}_{1}^{\prime} \lg t^{\prime}+\mathrm{K}_{1}^{\prime \prime}\right] \\
& \quad+n_{2}\left[\mathrm{R} t^{\prime} \lg \frac{m_{2}^{\prime}}{v^{\prime}}+\left(\mathrm{R}+\mathrm{K}_{2}{ }^{\prime}\right) t^{\prime}-\mathrm{H}_{2}{ }^{\prime} \lg t^{\prime}+\mathrm{K}_{2}{ }^{\prime \prime}\right] \\
& \quad=n_{3}\left[\mathrm{R} t^{\prime} \lg \frac{m_{3}{ }^{\prime}}{v^{\prime}}+\left(\mathrm{R}+\mathrm{K}_{3}{ }^{\prime}\right) t^{\prime}-\mathrm{H}_{3}^{\prime} \lg t^{\prime}+\mathrm{K}_{3}^{\prime \prime}\right],
\end{aligned}
$$


or

$$
\begin{aligned}
& \lg \frac{\left(\frac{m_{1}^{\prime}}{v^{\prime}}\right)^{n_{1}} \cdot\left(\frac{m_{2}^{\prime}}{v^{\prime}}\right)^{n_{2}}}{\left(\frac{m_{3}^{\prime}}{v^{\prime}}\right)^{n_{3}}} \\
& \quad=\frac{1}{\mathrm{R} t^{\prime}}\left[\left(n_{3} \mathrm{~K}_{3}{ }^{\prime}-n_{1} \mathrm{~K}_{1}{ }^{\prime}-n_{2} \mathrm{~K}_{2}{ }^{\prime}\right) t^{\prime}-\left(n_{2}+n_{1}-n_{3}\right) \mathrm{R} t^{\prime}\right. \\
& \left.+\left(n_{1} \mathrm{H}_{1}^{\prime}+n_{2} \mathrm{H}_{2}{ }^{\prime}-n_{3} \mathrm{H}_{3}{ }^{\prime}\right) \lg t^{\prime}+\left(n_{3} \mathrm{~K}_{3}^{\prime \prime}-n_{1} \mathrm{~K}_{1}^{\prime \prime}-n_{2} \mathrm{~K}_{2}{ }^{\prime \prime}\right)\right] .
\end{aligned}
$$

i.e., the fact that each of the components has two potentials instead of one does not therefore affect the form of the equation obtained for chemical equilıbrium.

Here $\left(\frac{m_{1}^{\prime}}{v^{\prime}}\right)^{n_{1}} \cdot\left(\frac{m_{2}{ }^{\prime}}{t^{\prime}}\right)^{n_{23}}:\left(\frac{m_{3}^{\prime}}{v^{\prime}}\right)^{n_{3}}$ gives the connexion between the concentrations of the gaseous substances expressed in gram-molecules per unit volume acting chemically one upon another under the action of light, which constitutes the law of mass-action in homogeneous systems;

$$
\left(n_{1} \mathrm{H}_{1}{ }^{\prime}+n_{2} \mathrm{H}_{2}{ }^{\prime}-n_{3} \mathrm{H}_{3}{ }^{\prime}\right) \lg _{2} t^{\prime}+\left(n_{3} \mathrm{~K}_{3}{ }^{\prime \prime}-n_{1} \mathrm{~K}_{1}{ }^{\prime \prime}-n_{2} \mathrm{~K}_{2}{ }^{\prime \prime}\right)
$$

the difference between the thermal energy of $n_{1}$ gram-mol. of $\sigma_{1}+n_{2}$ gram-mol. of $\sigma_{2}$ and the thermal energy of the product of their combination $\left(n_{3}\right.$ gr.-mol. of $\sigma_{3}$ ) in light of a given intensity and composition, i. e., is the heat of reaction (let it be denoted by $Q_{r}$ ) in light, when $n_{1}$ gr.-mol. of $\sigma_{1}+n_{2}$ gr.-mol. $\sigma_{2}$ transform into $n_{3} \mathrm{gr} .-\mathrm{mol}$. of $\sigma_{3}$; $n_{3} \mathrm{~K}_{3}^{\prime \prime}-n_{1} \mathrm{~K}_{1}{ }^{\prime \prime}-n_{2} \mathrm{~K}_{2}^{\prime \prime}=\mathrm{K}^{\text {iv }}$ is a constant; $-\left(n_{1}+n_{2}-n_{3}\right) \mathbf{R} t^{\prime}$ is the work done by the system or against the same during the same transformation in light, and $t^{\prime}$ is the absolute temperature.

'Thus an ordinary consideration of Gibbs' equations under the modified conditions (i. e., when each component gets under. the action of light a light-kinetic potential besides its modified chemical potential) shows that the connexion between the logarithm of $\left(\frac{m_{1}^{\prime}}{v^{\prime}}\right)^{n_{1}} \cdot\left(\frac{m_{2}{ }^{\prime}}{v^{\prime}}\right)^{n_{2}}:\left(\frac{m_{3}^{\prime}}{v^{\prime}}\right)^{n_{3}}$, or the logarithm of the constant of chemical equilitrium in homogeneous systems in light, the heat of reastion or of transformation of $n_{1} \sigma_{1}+n_{2} \sigma_{2}$ into $n_{3} \sigma_{3}$ in light, the catemal work done by the system or against the same dining the reaction, and the absolute temperature remains the same and follows in light the same lano as in the dark,-i. e., a system which is in equilibrium in the dark, when exposed to light passes under the influence of the some only to a new point of equilibrium, has a new constant of 
equilibrium, new heat of reaction, \&e., but the connexion between the logarithm of the constant of equilitrium, the lieat of reaction, absolute temperature, will always, nevertheless, be governed by the same law. Since different intensities and different wavelengths differently affect the values of the chemical and light-kinetic potentials, \&c., they will evidently also differently change the values of the different parts of the equation $(\Omega)$.

Thus, having a reversible system $n_{1} \sigma_{1}+n_{2} \sigma_{2}=n_{3} \sigma_{3}$, and an equation $n_{1}\left(\mu_{1}{ }^{\prime}+\lambda_{1}{ }^{\prime}\right)+n_{2}\left(\mu_{2}{ }^{\prime}+\lambda_{2}{ }^{\prime}\right)=n_{3}\left(\mu_{3}{ }^{\prime}+\overleftarrow{\lambda_{3}{ }^{\prime}}\right)$ in light instead of $n_{1} \mu_{1}+n_{2} \mu_{2}=n_{3} \mu_{3}$ in the dark, it will depend upon the values of the indiridual potentials of all components in which direction the equilibrium will shift. 'The sime will be the case when the system is brought from light of one intensity or composition into light of another intensity or composition, the point of equilibrium being for given conditions always a fixed one.

A short notice in a letter from Professor van't Hoff leads me to think that a genoral "principle of movalle equilibrium" can be estabiished for light, as it was set up by van't Hoff for heat. I am not sure that this was what van't Hoff meant. In the system $\mathrm{CO}+\mathrm{Cl}_{2}=\mathrm{COCl}_{2}, \mathrm{H}_{2}+\mathrm{Cl}_{2}=2 \mathrm{HCl}$, it is the $\mathrm{Cl}_{2}$ which absorbs light most. Having a system $\mathrm{CO}, \mathrm{Cl}_{2}$, $\mathrm{COCl}_{2}$ or $\mathrm{H}_{2}, \mathrm{Cl}_{2}, \mathrm{HCl}$ in the dark, they do not act one upon another, but on exposure to light $\mathrm{COCl}_{2}$ or $\mathrm{HCl}$ is formed, i.e., the system is shilted from the left to the right. Again, in the system $\mathrm{AgCl}$ (in light) $=\mathrm{Ag}+\mathrm{Cl}_{2}$ (in light), it is the $\mathrm{AgCl}$ which absorbs light most, and the light has the effect of forming $\mathrm{Ag}$ and $\mathrm{Cl}_{2}$ from $\mathrm{AgCl}$, and not the opposite. Since all substances absorb light, this leads to the conclusion that "each kind of' equilibrium between two states of" matter (system) becomes at a constant volume on exposure to light shiffed in the direction which is accompanied by the greuter alsorption of lighte." Van't Hoff's principle for heat, paraphrased, is : "Each kind of equilibrium between two different states of matter (system) becomes at a constant volume on exposure to a higher temperature (heat) shifted in the direction which is accompanied by the absorption of heat."

From the above principle, further conclusions can be drawn about the influence which the intensity of light and its composition must lave upon the point of equillibium. The greater the intensity of light, the greater the influence of a given wavelength upon the constituents of the system, the greater is the maximum kinetic energy stored in the atoms and molecules, and it is natural to expect that the substance which absorbs light most has also a greater increase in the values of the 
potentials, i. e., the greater the increase of the intensity of light, \&c., the more the equilibrium will be shifted from the left to the right: more $\mathrm{AgCl}$ will be decomposed. In the case of $\mathrm{H}_{2}+\mathrm{Cl}_{2}=2 \mathrm{HCl}$ and $\mathrm{CO}+\mathrm{Cl}_{2}=\mathrm{COCl}_{2}$, since the reaction of decomposition of $\mathrm{COCl}_{2}$ and of $\mathrm{HCl}$ in light is in any ease infinitely small, this will show itself in an increase of the velocity of combination of $\mathrm{CO}$ and $\mathrm{Cl}_{2}$ or of $\mathrm{H}_{2}, \mathrm{Cl}_{2}$, as is actually the case. What is the more precise connexion between the constant of equilibrium and the intensity of light? This is a problem which will require long, patient, and most difficult experimental investigation. The author is now endeavouring to approach step by step the solution of this problem. Starting first with the study of one of the simplest cases of equilibrium, namely, with the effect of the intensity of light upon metallic plates of the same kind, mentioned above, the author, being in possession of a constant powerful source of light, was able to establish the fact that the electromotive force, which in the same manner as the constant of equilibrium gives the maximum work, is directly proportional in this case to the intensity of light. A more exact investigation of the results obtained and on a larger experimental basis is, however, needed, may to some small extent modify this conclusion, and will be communicated in due time.

Returning to the equation $(\Omega)$, we further get that if no work is done by or against the system during the reaction, i. e., at a constant volume $\left(n_{2}+n_{1}-n_{3}\right) \mathbf{R} t^{\prime}=0$, and the total heat-energy of the given gas can be put (approximately at any rate $)=\mathrm{C}_{s} t^{\prime}$, where $\mathrm{C}_{*}$ is the specific heat of the givell gas in light at a constaut volume, and we get, after contracting the constants, instear of equation $(\Omega)$,

$$
\lg \frac{\left(\frac{m_{1}^{\prime}}{v^{\prime}}\right)^{n_{1}} \cdot\left(\frac{m_{2}^{\prime}}{v^{\prime}}\right)^{n_{2}}}{\left(\frac{m_{3}^{\prime}}{v^{\prime}}\right)^{n_{3}}}=\frac{1}{\mathrm{~K}}\left(\mathrm{~K}^{\prime \prime \prime}+\mathrm{B} \operatorname{gg} t^{\prime}-\frac{\mathrm{A}}{t^{\prime}}\right), .
$$

which, differentiated with respect to $t^{\prime}$, gives

$$
\begin{aligned}
& \frac{d\left[\lg \frac{\left(\frac{m_{1}^{\prime}}{v^{\prime}}\right)^{m_{1}} \cdot\left(\frac{m_{2}{ }^{\prime}}{v^{\prime}}\right)^{n_{2}}}{\left(\frac{m_{3}^{\prime}}{v^{\prime}}\right)^{n_{3}}}\right]}{d t^{\prime}} \\
& =\frac{\left(n_{3} \mathrm{~K}_{3}^{\prime \prime}-n_{1} \mathrm{~K}_{1}^{\prime \prime}-n_{2} \mathrm{~K}_{2}^{\prime \prime}\right)+\left(n_{1} \mathrm{C}_{1}+n_{2} \mathrm{C}_{2}+n_{0} \mathrm{C}_{3}\right) t^{\prime}}{\mathrm{R} t^{\prime 2}}=\frac{\mathrm{A}+\mathrm{B} t^{\prime}}{\mathrm{R} t^{\prime 2}},
\end{aligned}
$$


which is van't Hoff's equation, i. e., the variation of the logarithm of the constant of chemical equilibrium in homogeneous (gaseous) systems with the variation of temperature must follow in the light the same law which it follows in the diark.

At a constant temperature equation $\Omega$ or $\Omega^{\prime}$ becomes

$$
\left(\frac{m_{1}{ }^{\prime}}{v^{\prime}}\right)^{n_{1}} \cdot\left(\frac{m_{2}{ }^{\prime}}{v^{\prime}}\right)^{n_{3}}:\left(\frac{m_{3}{ }^{\prime}}{v^{\prime}}\right)^{n_{3}}=\text { const., . . }
$$

i. e., the law of mass-action must hold good for equilibrium in homogeneous systems, when the equilibrium is shifted under the action of light to a new point in the same manner as in the dark. This is exactly what was found to be the case in the experimental part of the paper" "On Chemical Dynamics and Statics under the Influence of Light," Phil. Trans. of the Royal Society, Oct. 1902 .

The above equation $\left(\Omega^{\prime \prime}\right)$ can in homogeneous systems be decomposed in the usual manner into two equations of two spposite velocities of reaction,

$$
\left(\frac{d x^{\prime}}{d \tau}\right)^{\prime}=\mathrm{C}^{\prime}\left(\frac{m_{1}^{\prime}}{v^{\prime}}\right)^{n_{1}} \cdot\left(\frac{m_{2}^{\prime}}{v^{\prime}}\right)^{n_{2}} \text { and }\left(\frac{d x}{d \tau}\right)^{\prime \prime}=\mathrm{C}^{\prime \prime}\left(\frac{m_{3}^{\prime}}{v^{\prime}}\right)^{n_{3}} \text {, }
$$

which at equilibrium become equal, i. e., the velocity of a chemical recution when caused (or influenced) by the light-energy introduced into the system follows in light the same law of mass-action as it follows in the dark, when a reaction is brought about by the intrinsic properiies of matter always existent in and inseparable from the same, and which we call chemical uffinity or chemical potential. This is just the prineipal result of the experimental researeh communicated in the abovementioned paper. No law analogous to Faraday's for electrolysis was found to hold good for light introduced into the system.

The experimental results obtained by the author thus led him gradually to believe that the light-energy introduced from an external source into the system does not act upon the same in a mamner similar to that of introduced electrical energy; that the above conceptions as to the mode of working of the introduced light upon a system must give the true state of things, the more so as they also furnish a rational and detailed explanation of the phenomena obtained with metallic plates when exposed to light, and of the phenomena of induction and deduction, which otherwise seem to be of a mysterious and complicated nature.

From this result follows further the conclusion, drawn already in the above-mentioned paper in connexion with Phil. Mag. S. 6. Vol. 5. No. 26. Feb. 1903. 
the chemical induction and chemical deduction periods (see p. 391):-

Since velocity of reaction follow: the law of action of mass. when the molecules taking part in the reaction lave attained, under the influence of light, a constunt value of their chemical potentials, the same law of mass-action must also be the governing principle for the velocity of reaction at any given moment of the chemical induction and deduction periods, only the velocity constant in the equation for velocity of reaction will vary as the chemical potentials of the reacting substances change.

Davy Faraday Laboratory of the

Royal̆ Institution, November 190\%.

XX. On a Determination of the Ratio of the Sprecipic Heats at Constant Pressure and at Constant Volume for Air and Steam. By Walter Makower, B.Sc., University College, London*.

\author{
[Plate I.] \\ 1. Introduction and Genesal Method.
}

THE method employed was similar to that used by 1 Lummer and Pringsheim 'Smithsonian Contributions to Knowledge, 1898), which consists in allowing the gas under investigation to expand adiabatically and measuring the lowering of temperature cansed by wuch expansion.

In these experiment- the initial and final pressures of the gas were measured on a sulphuric acid gauge, and the change of temperature deduced from the variation of the electrical resistance of a fine platinum-bolometer strip immersed in the gas under investigation. The gases experimented upon were air, oxygen, carbon dioxide, and hydrogen, for which the values of the ratio of the two -pecific heats were found to be $1 \cdot 4025,1 \cdot 3977,1 \cdot 2995,1 \cdot 4084$ respectively.

The chief modifications introduced in the present investigation consist in the substitution of a platinum-thermometer with compensating leads, for the bolometer-strip of Lummer and Pringsheim, who employed a somewhat different device for eliminating errors due to conduction of heat along the leads. Also, at the suggestion of Prof. Callendar, the electrical contacts were made by means of a specially constructed automatic mereury switch, instead of by hand. It was also hoped that it might be possible to use smaller quantities of gas than Lummer and Pringsheim had used, and it was

* Communicated by the Physical Society : read Norember 14, 1902. 